\title{
Design of Essential Elements Involved in China's Carbon-Tax Taxation System and Its Implementation Strategies
}

\author{
Aiwen Zhao*, Ruilin Li \\ Xuzhou Institute of Technology School of Economics, Jincheng College, Nanjing University of Aeronautics and Astronautics, \\ Nanjing, China \\ Email: *xzzhaoaiwen@163.com
}

How to cite this paper: Zhao, A.W. and $\mathrm{Li}$, R.L. (2019) Design of Essential Elements Involved in China's Carbon-Tax Taxation System and Its Implementation Strategies. Low Carbon Economy, 10, 47-58. https://doi.org/10.4236/lce.2019.102004

Received: March 22, 2019

Accepted: June 27, 2019

Published: June 30, 2019

Copyright $\odot 2019$ by author(s) and Scientific Research Publishing Inc. This work is licensed under the Creative Commons Attribution International License (CC BY 4.0).

http://creativecommons.org/licenses/by/4.0/

\begin{abstract}
Based on a series of theoretical study of Pigou tax principle, polluter pays principle (PPP), double dividend theory, tax incidence and tax burden transfer, carbon tax excess burden, and the Laffer curve, this article determines the design of essential elements involved in carbon tax system, including the scope of carbon tax, the objects of Taxation, the tax payer, the tax link, the tax rate, and the tax preference, etc. Meanwhile, some principles are proposed when implementing strategies, that is, the principle of combination of efficiency and equity, the principle of tax rate dynamic adjustment, and the principle of tax neutrality.
\end{abstract}

\section{Keywords}

Carbon-Tax Taxation System, Tax Incidence, Implementation Strategy

\section{Introduction}

As noted in the 19th CPC Congress Report, great efforts should be focused on addressing outstanding environmental issues, including "continuing air pollution control actions, and winning the Battle of the Blue Sky", "upgrading pollution emission standards", "strengthening the liability of polluters" and "inflicting severe punishment", and the like. The issue of environmental governance has become increasingly attractive. The Environmental Protection Tax of the People's Republic of China was officially introduced on January 1, 2018 after a long-run deliberation. The taxable items include atmospheric pollutants, water contaminants, solid waste and noise pollution. The tax is stipulated to be levied on the pollutants in a short term, which is expected to be controlled effectively in 
10 years or so. The Atmospheric pollutants involved in environmental tax include 44 toxic gases, such as $\mathrm{SO}_{2}, \mathrm{NOx}, \mathrm{CO}$ and $\mathrm{Cl}_{2}$ while $\mathrm{CO}_{2}$ is excluded though it causes the greenhouse effect. For this reason, the reform of "tax for fees" cannot be applied to $\mathrm{CO}_{2}$ and carbon-tax is thus given special concern as an independent tax choice. The process of developing carbon-tax started from public rejection by the Ministry of Finance and finally to acceptance by the NDRC, full of ups and downs.

The study of carbon-tax was initiated by scholars out of China, with the earliest research conducted by Pigou [1] in terms of its externality and its correction. Sandmo [2] first proposed the idea of an environmental tax rate under the general equilibrium framework, with the result showing that the tax rate is not equal to the tax rate of the ancient API. Owen A D [3] noticed the fact that the impact of excessive carbon-tax rates on underdeveloped areas was significantly higher than that of developed regions. Therefore, relatively low tax rates should be designed for underdeveloped areas in order to allow regional economic growth, regionally coordinated development and carbon reduction targets to coexist. The carbon-tax-related study is a newly developed research field in China and is just in its start-up step. Yiu Xin and Liu Xiying [4], with the help of DICE model, estimated the optimal carbon-tax rate by solving the dynamic optimal carbon-tax model of growth constraint based on benefit maximization. The results demonstrated that in order to avoid the large economic shock China's optimal carbon-tax system should be specially designed as a dynamic and gradual process. Xiang Yong [5] believed that when levying carbon-tax, Chinese government should set varying tax rates according to different regional economic development levels, with the aim of achieving regional economy's coordination. Fan Yunqi [6] introduced energy elements and carbon-tax effect to the total production function, formulated a dynamic optimal carbon-tax model based on benefit maximization under environmental constraints, and worked out the optimal carbon-tax rate. The results showed that tax preferential policies should be implemented to avoid excessive impact on the economy in the early stage, and meanwhile the principle of "common and differentiated responsibilities" and "respective capabilities" should be followed in determination of carbon tax rates. Mao Yanhua and Qian Binhua [7] divided China into eight major economic regions, for which a common but differentiated carbon-tax rate was suggested be applied, respectively. Xu Yingzhi and Zhou Xiuli [8], strictly following the principle of "sharing between producers and consumers", simulated the optimal carbon-tax under different constraints bu using multi-objective input-output model. Furthermore, they compared the effects of carbon-tax collection on $\mathrm{CO}_{2}$ emissions, total output level and energy consumption at different tax rates. Zhang Jincan and Zhong Weizhou [9] discussed the influential factors that determined the optimal carbon-tax rate via the static game model of complete information. By referring to studies both at home and abroad, the authors analyze the carbon-tax design in theory, followed by its elements' design, and finally suggest implementation strategies. 


\section{Theoretical Basis of Carbon-Tax Design}

Finland is the earliest country that introduced a carbon tax in 1990. After that, many developed countries have begun to adopt carbon-tax gradually. In general, a carbon tax is the one that is levied on fossil fuels such as coal, oil and natural gas at a fixed rate according to their carbon content. The reason why many a theory has supported this practice is an initial purpose of alleviating negative externality of our environment.

\subsection{Pigou Tax Principle}

The Pigou tax was first proposed by British welfare economist Pigou (1877-1959) as an economic means of controlling environmental pollution, which is levied on polluters in accordance with the degree of harm caused by pollution incurred. The tax revenue is then used to make up for the gap between the polluters' manufacturing cost and social cost. Overall, the Pigou tax helps achieve an effective allocation of resources, with pollution reduced to the optimal level of Pareto. It is statically advantageous. That is, enterprises will make every effort to reduce pollution since tax is levied whenever pollution is generated by them. From a dynamic angle, when the tax rates remain unchanged, enterprises may also try hard to reduce expected charges of taxes in future through technological upgrading. In a word, the Pigou tax is characterized by an effective combination of static efficiency and dynamic efficiency.
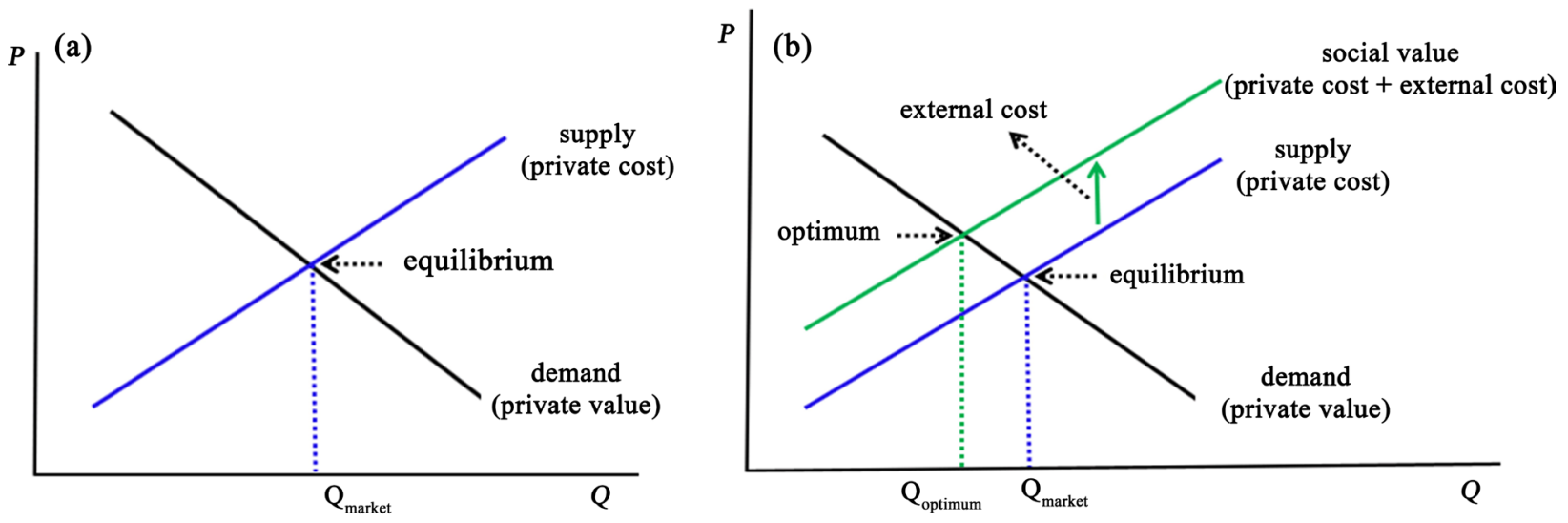

(c)

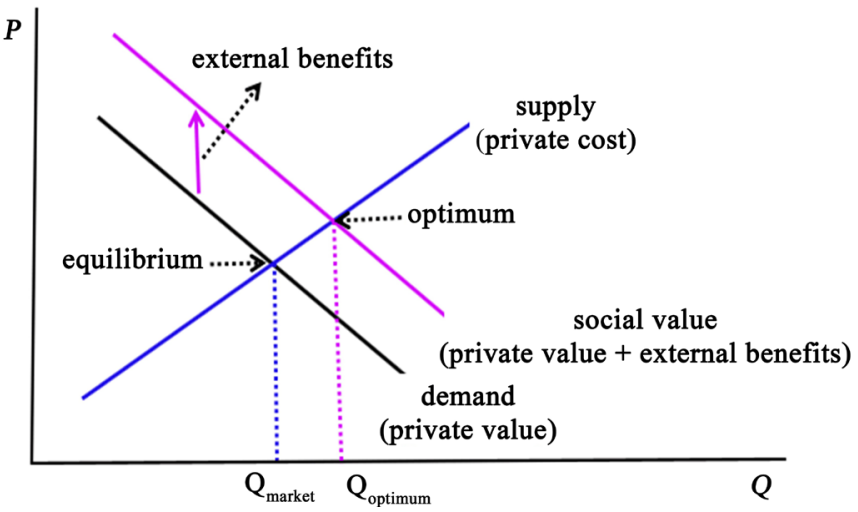

Figure 1. (a) Situations without externality involved; (b) Negative externality (taxation); (c) Positive externality (subsidy). 
An externality is the cost or benefit that affects a party who did not choose to incur that cost or benefit. It is formally divided into positive and negative ones, which depends on whether an economic activity imposes a favorable or unfavorable effect on an unrelated third party. Seen from Figures 1(a)-(c), the market equilibrium is efficient without externality involved. For Figure 1 (b), the manufacturers directly discharge pollutants, imposing a bad impact on the surrounding environment, that is, negative externality. Also in Figure 1(b), the demand curve represents private value, the value to consumers (that is, their willingness to pay), and the supply curve represents private cost, the costs borne directly by the producer, which mutually denote the social cost of production. In the case of negative externality, social costs $=$ private costs + external costs. And the social cost curve is above the supply curve because we take into account the external costs that the producer brings to the society. The difference between the two curves reflects the external cost of emissions, the so-called Pigou tax. However, Figure 1(c) covers the industries or manufacturers that are characterized by energy conservation and environmental protection. Contrary to contaminative ones, they generate positive externality, instead. In Figure 1(c), the demand curve represents private value while the supply curve represents private cost. In the case of positive externality, social value $=$ private value + external interest. As shown, the social value curve is located above the demand curve because the external benefits that producers bring to society are considered. The gap between these two curves reflects the external benefits, namely subsidies. To sum up, in order to internalize the externality, such measures should be taken to levy on the goods with negative externality but to allow subsidies to those with positive externality.

\subsection{Polluter Pays Principle (PPP Principle)}

The Economic Cooperation and Development (OECD) introduced the Polluter Pays Principle (PPP) in the 1970s, requiring any polluter to pay for the pollution that he has caused either directly or indirectly, which is actually an application of the Pigou tax theory. The environmental pollution, referred to as one of public goods, is characterized by its externality, which usually results in the fact that individuals or organizations that emit pollution are more likely to evade responsibility. Therefore, if they are charged a certain sum for pollution, any cost they incur from pollution may be borne by themselves through internalization of external costs. Accordingly, such an increase in internal costs will influence polluters in their behavior and/or decision-making, and then will encourage them to reduce emissions and increase efficiency, ultimately achieving an effective allocation of environmental resources in economy.

Since the individuals or organizations that emit $\mathrm{CO}_{2}$ to achieve more benefits or higher effectiveness ultimately increase social cost they should be held responsible for their behaviour, which is measured by the degree of harm. To sum up, the carbon tax levied based on the amount of $\mathrm{CO}_{2}$ emission exemplifies the positive correlation between obligation and responsibility. 


\subsection{Double Dividend Theory}

The "double dividend" derived from environmental tax implies that the introduction of environmental tax may not only effectively suppress pollution, improve the quality of the ecological environment, and achieve the goal of environment protection, but thanks to tax revenue, it may also help ease the situation where the capital and labor is distorted by the existing tax system. Thus, "green dividends" and "blue dividends" are expected to be achieved as social employment is solved and social economy grows steadily.

Following the introduction of environmental tax theory, in early 1990, David W. Pearce (1991) initially proposed the "double dividend" theory related to a carbon tax, which insisted that carbon tax revenue be applied to reduce the existing tax rate, e.g. the welfare cost of income tax or capital tax. The "double dividend" theory is commonly acceptable to many economists who believe that such environmental taxes can replace other distorted taxes. However, some scholars are still skeptical about effectiveness of this theory.

\subsection{Carbon-Tax Imposition Incidence}

(1) Difference of carbon-tax imposition between consumers and manufacturers

It can be seen from Figure 2(a) and Figure 2(b) that when no tax, is levied, there exists equilibrium point $\mathrm{E}$, the equilibrium price $P_{E}$, and the equilibrium quantity $Q_{E}$.

Figure 2(a) illustrates the situation where customers are taxed. The supply curve $S_{1}$ remains unchanged while the demand curve moves downward from $D_{1}$ to $D_{2}$ with a range of $\mathrm{T}$ owing to the tax revenue from consumers. And a new equilibrium point emerges, called $E^{*}$, at the place where $D_{2}$ meets $S_{1}$. Besides, as soon as consumers are taxed, the price offered to manufactures becomes $P_{S}$ rather than $P_{E}$, between which the difference is the tax borne by the manufactures, denoted as $P_{E}-P_{S}$. Similarly, the charges paid by the consumers' changes from $P_{E}$ to $P_{B}$, resulting in a gap of $P_{B}-P_{E}$, namely the tax burden on them.

Figure 2(b) shows the situation where manufactures are taxed. The demand curve $D_{1}$ remains unchanged while the supply curve moves upward from $S_{1}$

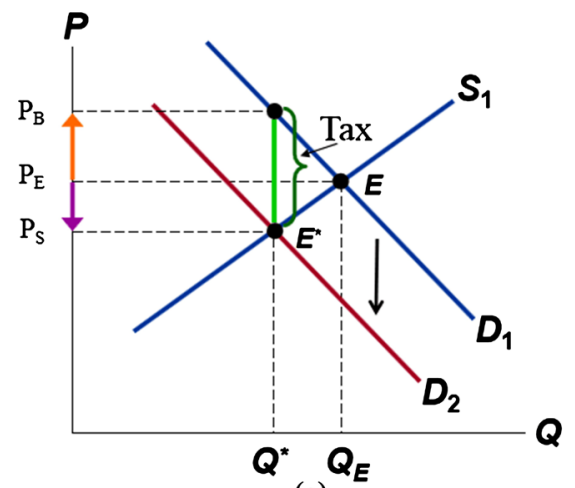

(a)

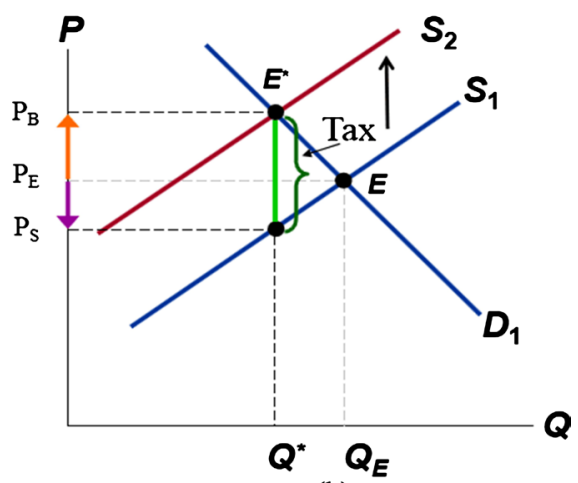

(b)

Figure 2. (a) Taxing consumers; (b) Taxing manufactures. 
to $S_{2}$ with a range of T owing to the tax revenue from manufactures. A new equilibrium point emerges at $E^{*}$ where curve $D_{1}$ meets curve $S_{2}$. In addition, after taxation the price for manufactures are no longer $P_{E}$, but $P_{S}$, leading to a gap of $P_{E}-P_{S}$, the tax borne by themselves. Meanwhile, the charges paid by consumers are $P_{B}$ rather than $P_{E}$. The difference between them is the tax levied by the consumers, denoted as $P_{B}-P_{E}$.

(2) Tax incidence and tax shifting

Seen from both Figure 2(a) and Figure 2(b), the tax burden is always shared by manufacturers and consumers no matter who is taxed. And how much tax is to be shared between them depends on the goods' elasticity of demand and supply.

Figure 3(a) introduces the situation where supply is elastic while demand is inelastic. Manufactures are pretty sensitive to price changes in goods (the supply curve appears flat) and consumers are not particularly sensitive (the demand curve appears steep). In this case, the tax burden caused by taxation is borne more by the consumers and less by the manufacturers.

Figure 3(b) explains another situation where supply is inelastic while demand is elastic. On the contrary, manufacturers are not sensitive to price changes in goods (the supply curve becomes steep) while consumers are especially sensitive (the demand curve is amortized). Thus, the tax burden caused by taxation is borne more by the manufacturers and less by the consumers.

From Figure 2 and Figure 3, it can be concluded that whether manufactures or consumers are taxed, the tax burden is mutually shared by the both. The tax amount borne by each depends on a real comparison between demand elasticity and supply elasticity. Basically, it falls more on the inelastic side characterized by a steeper curve and less sensitivity to price.

The analysis results tell the truth that it makes no difference whether the carbon-tax imposition is effected in production or consumption.

\subsection{Higher Carbon Tax Rate May Not Always Be Favorable}

(1) Carbon taxes generate a tax excess burden

Tax revenue increases considerable income to a country but simultaneously generates an excessive tax burden. The welfare economics shown below is applied to

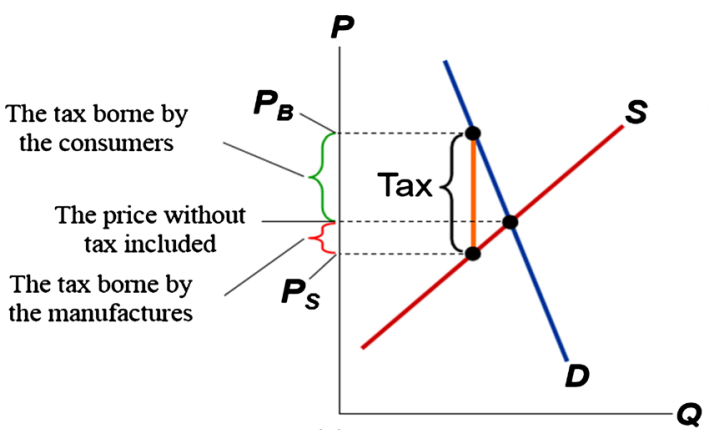

(a)

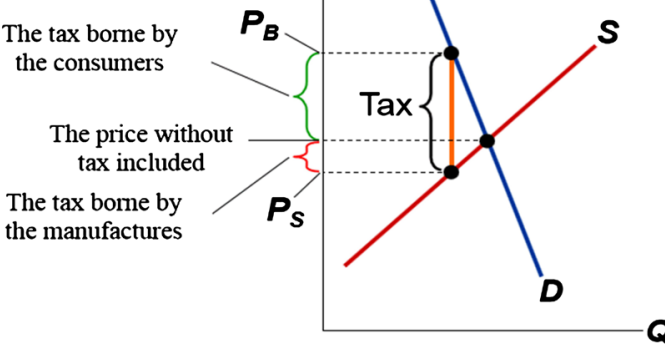

(b)

Figure 3. (a) The supply being elastic but demand inelastic; (b) The supply being inelastic but demand elastic. 
measure the benefits and losses gained or incurred from taxation.

Figure 4(a) describes the situation where the consumer surplus $\mathrm{CS}=\mathrm{A}+\mathrm{B}+$ $\mathrm{C}$, the manufacture surplus $\mathrm{PS}=\mathrm{D}+\mathrm{E}+\mathrm{F}$, and the total surplus $=\mathrm{CS}+\mathrm{PS}=\mathrm{A}$ $+\mathrm{B}+\mathrm{C}+\mathrm{D}+\mathrm{E}+\mathrm{F}$. In this case, the tax revenue is zero.

In Figure 4(b), the consumer surplus $C S=A$, the manufacture surplus $P S=$ $\mathrm{F}$, and the total surplus $=\mathrm{CS}+\mathrm{PS}=\mathrm{A}+\mathrm{B}+\mathrm{D}+\mathrm{F}$. The tax revenue gained herein is $\mathrm{B}+\mathrm{D}$, resulting in a reduction in total surplus of $\mathrm{C}+\mathrm{E}$, called deadweight loss of taxes, also perceived as the excessive burden of taxes caused by market distortions (Table 1).

Here is the correlation between tax scale and tax overburden, the correlation between tax scale and tax revenue as follows.

First of all, the correlation between the tax scale and tax overburden is learned from Figures 5(a)-(c). If each unit of goods is taxed $T$, then the excessive tax burden is denoted as the area of a small triangle; if double-tax is levied, then the excessive tax burden is four times the original; if the tax is levied as much as three times than before, then tax burden is nine times the original. To sum up, with the amplification of tax scale, the excessive tax burden increases much faster.

Next, the correlation between the tax scale and tax revenue is illustrated in Figures $6(\mathrm{a})-(\mathrm{c})$. When the tax scale grows from $\mathrm{T}$ to $2 \mathrm{~T}$, the tax revenue goes up increasingly; when it grows from $2 \mathrm{~T}$ to $3 \mathrm{~T}$, the tax revenue decreases, instead. Especially Figure 6(c), known as the Laffer curve, reveals the correlation between the tax scale and tax revenue. The fact is that larger tax scale is not always favorable. When the scale level is $T^{*}$, the tax revenue reaches its peak. And with the amplification of tax scale, the tax revenue declines, instead.

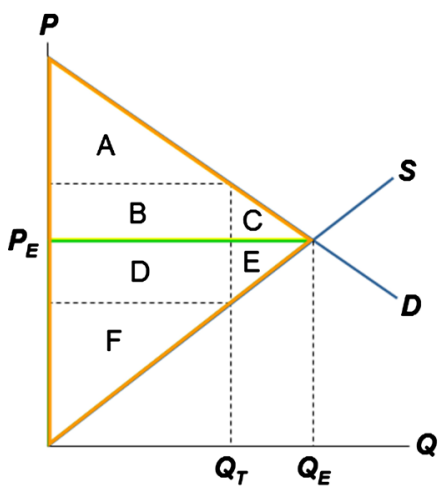

(a)

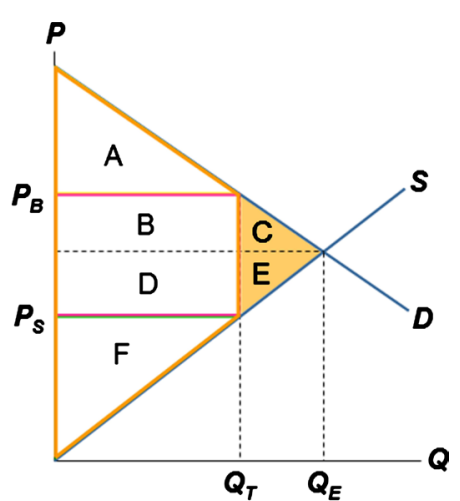

(b)

Figure 4. (a) The situation without taxation; (b) The situation with taxation.

Table 1. How taxation influences welfare.

\begin{tabular}{cccc}
\hline & No taxation & Taxation & Change \\
\hline Consumer surplus & $\mathrm{A}+\mathrm{B}+\mathrm{C}$ & $\mathrm{A}$ & $-(\mathrm{B}+\mathrm{C})$ \\
Manufacture surplus & $\mathrm{D}+\mathrm{E}+\mathrm{F}$ & $\mathrm{F}$ & $-(\mathrm{D}+\mathrm{E})$ \\
Tax revenue & 0 & $\mathrm{~B}+\mathrm{D}$ & $+(\mathrm{B}+\mathrm{D})$ \\
Total surplus & $\mathrm{A}+\mathrm{B}+\mathrm{C}+\mathrm{D}+\mathrm{E}+\mathrm{F}$ & $\mathrm{A}+\mathrm{B}+\mathrm{D}+\mathrm{F}$ & $-(\mathrm{C}+\mathrm{E})$ \\
\hline
\end{tabular}




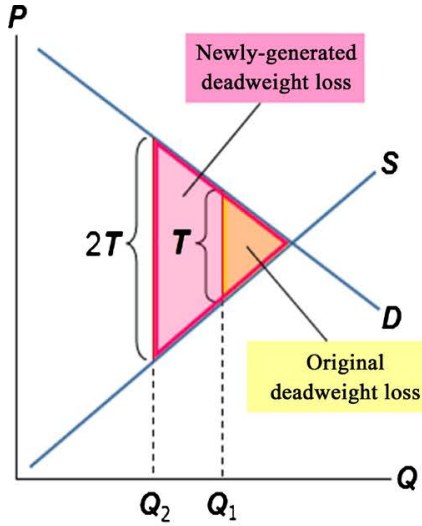

(a)

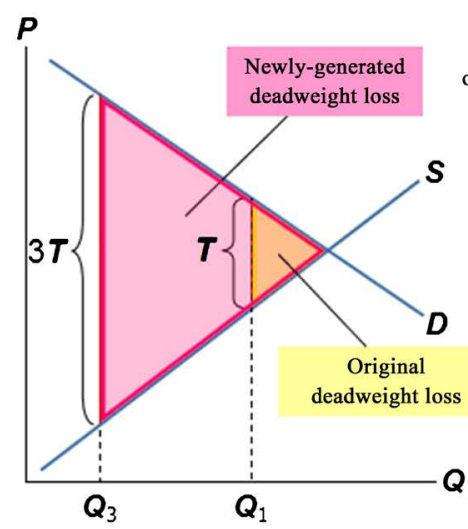

(b)

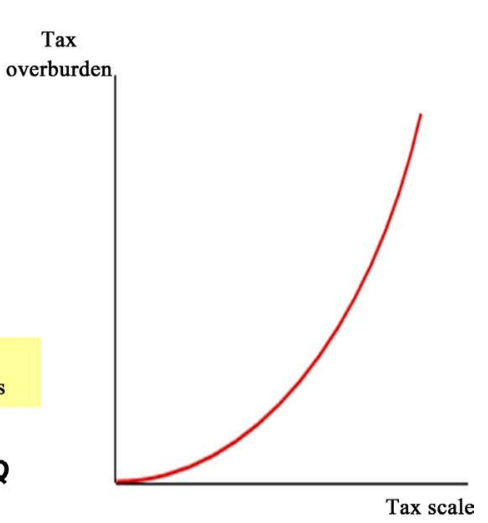

(c)

Figure 5. (a) The correlation between tax scale and tax overburden; (b) The correlation between tax scale and tax overburden; (c) The correlation between tax scale and tax overburden.

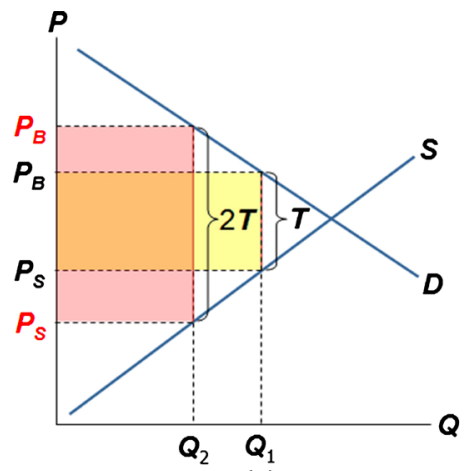

(a)

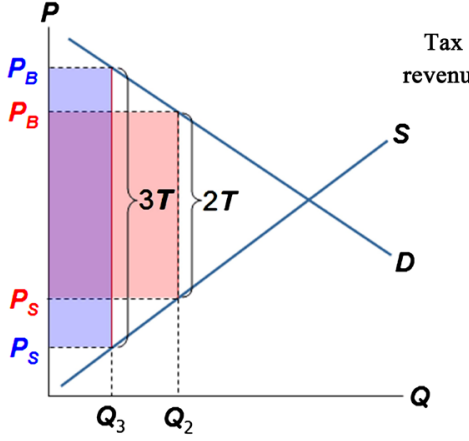

(b)

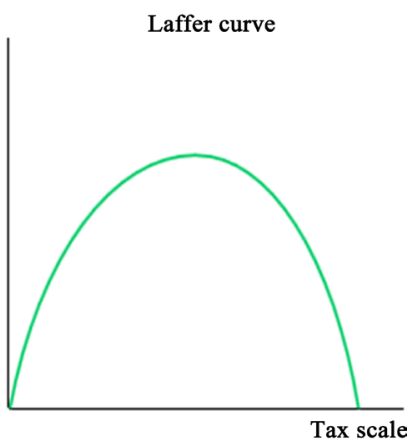

(c)

Figure 6. (a) The correlation between tax scale and tax revenue; (b) The correlation between tax scale and tax revenue; (c) The correlation between tax scale and tax revenue.

\section{Element Design for Carbon-Tax Imposition System}

\subsection{Taxation Scope and Object}

The taxation scope and subject is targeted at $\mathrm{CO}_{2}$ that is emitted directly to the natural environment from consumption of fossil fuels in the process of production and operation. Since $\mathrm{CO}_{2}$ results from usage of fossil fuels, the subject of carbon-tax will actually end up on fossil fuels such as coal, natural gas and refined oil.

\subsection{Taxpayers}

Taxpayers are the organizations and individuals that directly discharge $\mathrm{CO}_{2}$ into the natural environment. Among them, the organizations include state-owned enterprises, collective enterprises, private enterprises, foreign-funded enterprises, foreign enterprises, joint-stock enterprises, other enterprises and administrative units, public institutions, military units, public organizations and other units.

\subsection{Single-Linked Taxation}

The single-linked taxation refers to the operation that taxation is effected either 
in production or in consumption link. In both cases, the tax burden of carbon-tax is ultimately shared by both manufactures and consumers, of which the proportion is determined by elasticity of demand and supply. Since $\mathrm{CO}_{2}$ emissions are difficult to calculate at the consumption stage, it is recommended to tax the coal, oil, natural gas and other fossil fuels consumed in the production stage for easy control starting from the source. In practice, the government may impose carbon taxes on coal, petroleum products and natural gas according to the tonnage of carbon dioxide generated per unit of fuel at the economic entry point of fossil fuel products. Meanwhile, taxes may also be levied on coal at the mine (where royalties have been collected) or at the coal plant, on petroleum products at the refinery and on imported fuel products at the border.

\subsection{Tax Rate}

The tax rate of carbon is closely related to the tax assessment basis. Since $\mathrm{CO}_{2}$ emissions are used as the tax assessment basis, and the ecological damage caused by $\mathrm{CO}_{2}$ emissions is directly connected with its amount, rather than its value, the carbon-tax is levied on specific basis at a fixed rate. As suggested by relevant panels of the Ministry of Finance, the carbon tax rate should start with 10 yuan per ton of carbon dioxide in a period to be set in 2012, and be increased to 40 yuan by 2020, while the project team of the Ministry of Environmental Protection Planning Institute calls for 50 yuan per ton of carbon dioxide.

\subsection{Tax Preference}

Energy-intensive industries are the ones that carbon taxation has the greatest impact on. To safeguard them in worldwide competition, the government should implement such protective policies as low tax rate and tax refund, together with some effective measures as to improve energy efficiency by adapting up-to-date technological innovation, and to increase the proportion of non-fossil energy by reducing the use of fossil energy. In addition, considering people's livelihood, particularly the low-income groups who will suffer from the taxation, carbon dioxide emissions from coal and natural gas consumed in their lives will not be taxed temporarily. Furthermore, for the enterprises who positively reduce emissions and recover $\mathrm{CO}_{2}$ and even meet certain standards will be allowed preferential tax reduction or exemption.

\section{Implementation Strategies of Carbon Taxation}

\subsection{The Principle of Efficiency and Fairness}

Efficiency and fairness are two basic principles of tax policy and tax system design, which are also the objectives to be achieved in taxation.However, they are often in conflict when implemented. That is, a higher efficiency usually accompanies sacrifice of fairness, while the realization of equity is often at the expense of efficiency. An optimal taxation is to achieve both efficiency and fairness together. The relevant research individually conducted by Speck [10], Callan [11], 
Ekins \& Dresner [12], Fan Yong et al. [13], and Zhang Xiaodi [14] reveals that carbon taxation will surely enlarge the difference in income distribution between capital and labor factors and thus increase the inequality of social income distribution. In this sense, carbon taxation has been believed to be digressive, resulting in distribution digressive, which is controversial to fairness. However, a mature and well-designed tax policy may compensate this defect through tax return and preferential policies to lessen inequity of carbon taxation and to achieve efficiency and fairness in the end.

\subsection{The Principle of Dynamic Adjusting Tax Rates}

The carbon-tax rate should be fixed either to reflect the marginal cost of $\mathrm{CO}_{2}$ emission reduction, or to consider its impact on macroeconomic and industrial competitiveness. Besides, the carbon-tax rate may be adjusted in accordance with such issues as economic and social development and international tax coordination. It is, therefore, needed to establish a dynamic adjustment mechanism for carbon tax rate. More precisely, at the introductory phase of carbon tax, we need to lower tax rate to reduce social resistance and negative impacts on national economy and energy-intensive industries, while at the same time to constantly enhance taxpayers' awareness of emission reduction and environmental protection. Then, with the gradual increase of carbon-tax rates, enterprises are encouraged to innovate in $\mathrm{R} \& \mathrm{D}$, by which energy efficiency will be improved and fossil energy will be less consumed since replaced by clean alternatives.

\subsection{The Principle of Tax Neutrality}

When levying carbon tax, many European and American countries reduce their personal income tax and social security tax burden to achieve tax neutrality. In today's Chins, the tax burden is relatively high overall, and the structural tax reduction of "replacing business tax with VAT" has greatly improved the vitality of enterprises. It is recommended for China, by referring to worldwide experience, to comply with the reform of "increase and decrease", namely reducing corporate revenue tax rates and individual income tax rates while allowing subsidies to environmental-friendly industries or enterprises. Implementation of these strategies will, therefore, reduce the regressive nature of carbon tax, alleviate the psychological pressure of carbon tax on taxpayers, and cut the cost occurred in tax reform.

\section{Conclusions}

This article focuses on the design of China's carbon tax system elements and its implementation strategy of carbon tax as well, followed by some conclusions below.

1) The carbon tax rate is advisable to be calculated on a quantitative basis at a fixed rate, growing gradually from the lowest to the highest.

2) The carbon tax is recommended to be levied in a single link, eg. the pro- 
duction link in which such fossil fuels as coal, oil and natural gas are to be levied from the source.

3) A low tax rate and tax rebate protection policy are necessary to be implemented in energy-intensive industries which need to maintain their competitiveness in the world's market. Meanwhile, these industries are also encouraged to implement technological innovation, improve energy efficiency, and reduce the use of fossil energy. With an eye to people's livelihood, $\mathrm{CO}_{2}$ emitted from people's daily life is not taxed.

\section{Limitations}

1) The study on carbon tax characterized by distribution regressiveness needs to be integrated with a quantitative rather than a qualitative way only. It is necessary to further explore the regressiveness of income tax distribution at a variety of tax rates, and how to reduce the regressiveness of carbon tax to realize efficiency and fairness.

2) It explains the fact only qualitatively that the carbon tax rate is not as high as possible. Besides, impact of different carbon tax rates on fossil energy consumption, macroeconomics, prices and inflation needs to be added. By doing so, we may in a good position to determine the optimal carbon tax rate, and to reduce the tax burden. At the same time, it is necessary to establish a dynamic adjustment mechanism for the carbon tax rate to adapt to social and economic development.

\section{Funding}

This paper is a phased result of the 2015 National Social Science Fund Project: A study on the economic effect of carbon tax under the constraint of carbon emission reduction (15bgl144).

\section{Conflicts of Interest}

The authors declare no conflicts of interest regarding the publication of this paper.

\section{References}

[1] Pigou, A.C. (1928) A Study in Public Finance. Macmillan and Co., London.

[2] Agnar, S. (1967) Optimal Taxation in the Presence of Externality. The Swedish Journal of Economics, 77, 86-98. https://doi.org/10.2307/3439329

[3] Owen, A.D. (2013) Economics Instruments for Pollution Abatement: Tradable Permits versus Carbon Taxes. In: Dorsman, A., Simpson, J. and Westerman, W., Eds., Energy Economics and Financial Markets, Springer, Berlin, Heidelberg, 91-106. https://doi.org/10.1007/978-3-642-30601-3_6

[4] Yao, X. and Liu, X. (2010) Study on Optimal Carbon Tax in China Based on Growth Perspective. Economic Research, 45, 48-58.

[5] Xiang, Y. and Ren, H. (2011) Analysis of the Effect of China's Carbon Tax Levy and Implementation Measures. Economic Research, 52-55. 
[6] Fan, Y. and Li, X. (2013) Model Design and Empirical Study of Optimal Tax Rate of Carbon Tax-Based on the Calculation of China's Provincial Panel Data. Review of Finance and Economics, 27-32.

[7] Mao, Y. and Qian, B. (2014) Study on the Tax Rate of Subregional Carbon Tax Based on CGE Model. Finance Research, 31-34.

[8] Xu, Y. and Zhou, X.-L. (2014) An Optimal Carbon Tax Simulation Based on the Principle of "Producer-Consumer Sharing". Journal of China University of Geosciences (Social Sciences Edition), 14, 36-44.

[9] Zhang, J.-C. and Zhong, W.-Z. (2015) Complete Information Static Game Analysis of Optimal Tax Rate of Carbon Tax. China's Population, Resources and Environment, 25, 53-58.

[10] Speck, S. (1999) Energy and Carbon Taxes and Their Distributional Implications. Energy Policy, 27, 659-667.

[11] Callan, T., Lyons, S., Scott, S., Tol, R.S.J. and Verde, S. (2009) The Distributional Implications of a Carbon Tax in Ireland. Energy Policy, 37, 407-412. https://doi.org/10.1016/j.enpol.2008.08.034

[12] Ekins, P. and Dresner, S. (2010) Achieving Fairness in Carbon Emissions Reduction. The Green Fiscal Commission Report.

[13] Fan, Y. and Zhang, H.-W. (2013) The Regressive Effect of Carbon Tax on the Income Distribution of Urban Residents and the Scheme Design of Carbon Subsidy. Economic Theory and Management, 81-91.

[14] Zhang, X. (2014) Measurement of the Impact of Carbon Tax on Price, Welfare and Equity. The Southern Economy, 58-73. 